\title{
Transradial access: state of the art
}

\section{Joško Bulum*}

University of Zagreb School of Medicine, University Hospital Centre Zagreb, Zagreb, Croatia
KEYWORDS: transradial access, cardiac catheterization.

CITATION: Cardiol Croat. 2018;13(1-2):25. I https://doi.org/10.15836/ccar2018.25

*ADDRESS FOR CORRESPONDENCE: Joško Bulum, Klinički bolnički centar Zagreb, Kišpatićeva 12, HR-10000 Zagreb, Croatia. / Phone: +385-98-1714-090 / E-mail: jbulum@gmail.com

ORCID: Joško Bulum, https://orcid.org/0000-0002-1482-6503

|IIIIIIIIIIIIIIIIIIIIIIIIIIIIIIIIIIIIIIIIIIIIIIIIIIIIIIIIIIIIIIIIIIIIIIIIIIIIIIIIIIIIIIIIIIIIIIIIIIIIIIIIIIIIIIII

In the last decade, cardiac catheterization with transradial access is increasingly being used and become a golden standard for performing percutaneous coronary interventions, especially in patients with acute myocardial infarction with ST elevation, primarily because of the few and easiest possible complications than the transfemoral access. One of the disadvantages of the transradial approach is the relatively high incidence of catheterization failure (from $1 \%$ to $5 \%$ ) which can be reduced by routine angiography of radial artery and by modification of the technique in the case of anatomic variations of the radial artery. ${ }^{1}$

According to the results of our retrospective research, the incidence of anatomical variations of the radial artery was $8.8 \%$, excluding the tortuosities with the incidence of $12.7 \%$ The most common complication of the transradial approach we want to avoid is the radial artery occlusion which is mostly asymptomatic and the frequency with the routine Doppler is about $5 \%$. Procedures that reduce the incidence of radial artery occlusion include routine use of heparin and vasodilators, the use of hydrophilic sheaths such as smaller diameter and the closure of the puncture point for neocclusive hemostasis devices.
RECEIVED:

February 4, 2018

ACCEPTED:

February 10, 2018

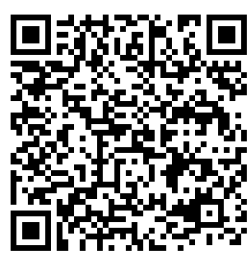

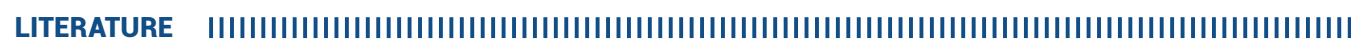
1. Kern MJ. The Interventional Cardiac Catheterization 2nd ed. St. Louis: Mosby; 2004. 